\title{
Sekreterlerin Yıldırmaya Maruz Kalma Düzeyleri: Bir Üniversite Hastanesi Örneği
}

\author{
Ebru BÜYÜKAYDIN** Gülcan ŞANTAŞ** $\quad$ Sidıka KAYA***
}

Geliş Tarihi (Received): 05.04.2017 - Kabul Tarihi (Accepted): 17.08.2017

\section{$\ddot{O} z$}

$\mathrm{Bu}$ çalışmanın amacı, bir üniversite hastanesinde görev yapan sekreterlerin yıldırmaya maruz kalma düzeylerini belirlemek ve yıldırmaya maruz kalma düzeylerinin çeşitli demografik özelliklere göre farklılaşıp farklılaşmadığını ortaya koymaktır. Çalışmada veri toplama aracı olarak "LIPT (Leymann Inventory of Psychological Terrorization) Ölçeği”" kullanılmıştır. Verilerin analizinde tanımlayıcı istatistiksel yöntemler, iki ortalama arasındaki farkın önemlilik testi, tek yönlü varyans analizi (ANOVA), Tukey testi, Kruskal Wallis varyans analizi ve çoklu doğrusal regresyon analizinden yararlanılmıştır. Çalışma sonucunda, hastanede çalışan sekreterlerin yıldırmaya maruz kalma düzeyleri $(4,52 \pm 0,60)$ genel olarak düşük düzeyde bulunmuştur. Sekreterlerin iletişim kurma olanağını hedef almaya yönelik davranışlara maruz kalma düzeylerinin $(4,21 \pm 0,81)$ en yüksek ve doğrudan sağlığını etkileyen davranışlara maruz kalma düzeylerinin $(4,86 \pm 0,32)$ en düşük olduğu tespit edilmiştir. Çoklu doğrusal regresyon analizi sonucunda, sosyal hayatı hedef almaya yönelik davranışlar boyutu dışındaki diğer 5 modelin istatistiksel olarak anlamlı olduğu görülmüştür $(F=1.929 ; p<0.005)$. Analiz sonucunda, lisans eğitim düzeyinde olanların lise eğitim düzeyine göre, bekârların evlilere göre ve poliklinik ve kliniklerde çalışanların diğer birimlerde çalışanlara göre yıldırmaya maruz kalma düzeyleri daha düşük bulunmuştur.

Anahtar Kelimeler: Sekreter, Yıldırma, Üniversite, Hastane, Sağlık Sektörü

\footnotetext{
* Hacettepe Üniversitesi, Basın ve Halkla İlişkiler Müdürlüğü, buyukaydin2@ gmail.com

** Arş. Gör., Hacettepe Üniversitesi, İktisadi ve İdari Bilimler Fakültesi, Sağlık Yönetimi Bölümü, gulcansantas@gmail.com

${ }^{* * *}$ Prof. Dr., Hacettepe Üniversitesi, İktisadi ve İdari Bilimler Fakültesi, Sağlık Yönetimi Bölümü, sdkaya@ hacettepe.edu.tr
} 


\title{
Mobbing Exposure Levels of Secretaries: A University Hospital Example
}

\begin{abstract}
The aim of this study is to determine the mobbing exposure levels of secretaries working in a university hospital and to determine whether their exposure to mobbing vary according to various demographic characteristics. "The Leymann Inventory of Psychological Terrorization Scale" was used as the data collection tool in the study. Data were analyzed using descriptive statistical methods, significance test of difference between two means, one way analysis of variance (ANOVA), Tukey test, Kruskal Wallis variance analysis and multiple linear regression analysis. As a result of the study, mobbing exposure levels of secretaries working at the hospital was generally low $(4.52 \pm 0.60)$. It has been found that mobbing exposure of secretaries in terms of behaviors towards targeting communication were at the highest level $(4.21 \pm 0.81)$ and mobbing exposure which affect direct health of the secretaries was found at the lowest level $(4.86 \pm 0.32)$. As a result of multiple linear regression analysis, it was found that 5 other models were statistically significant $(\mathrm{F}=1.929, \mathrm{p}<0.005)$. As a result of the analysis, mobbing exposure level was found to be lower in secreteries who were in undergraduate level of education according to high school education, single according to married, and secreteries working in outpatient clinics and clinics according to other units.
\end{abstract}

Keywords: Secretary, Mobbing, University, Hospital, Health Sector 


\section{Giriş}

Sağlık hizmetlerinin bir ekip işi olduğu ve her bir paydaşın hizmet sunumunda önemli olduğu düşünüldüğünde, sekreterlerin rol ve görevlerinin de önemi anlaşılmaktadır. Hastanede çalışan sekreterler, teşhis tedavi, hastanın izlenmesi, gerekli malzeme temini gibi konularda yazışmalar, dosyalama ve arşivleme gibi hizmetleri sunmaktadırlar (Tengilimoğlu ve Köksal, 2013, s. 35). Sekreterlik hizmetleri, genellikle hasta ve hasta yakınının sağlık kurumu ile iletişim kurduğu ilk hizmet alanıdır (Baran, Zincirkıran, \& Tiftik, 2010, s. 1). Sekreterler, hasta, hekim ve diğer sağlık çalışanları arasında iletişimde çoğunlukla köprü görevi görmektedir (Çakıroğlu ve Tengilimoğlu, 2014, s. 168).

Sekreterler, hizmet sunarken değer, saygı ve takdir görmeyi beklemektedirler. Ancak bu beklentiler gerçekleşmediğinde ve üstelik yönetim ve çalışma arkadaşları tarafından yıldırmaya maruz bırakıldıklarında, bu durum sunacakları hizmetin kalitesini ve hastayla kurdukları iletişimin niteliğini de etkileyebilir. Hastanelerde çalışan sekreterlerin çalışma ortamında yaşadıkları sorunlara değinen çalışma sayısı oldukça sınırlıdır. Üniversite hastanesinde görev yapan sekreterlerin yıldırmaya maruz kalma düzeylerinin ele alındığı bu çalışma ile alana katkı sağlanması hedeflenmektedir.

\section{Kavramsal Çerçeve}

Yıldırma, kişi ve grupların belirli bir kişiye yönelik sistematik bir şekilde düşmanca ve etik olmayan şekilde davranması olarak tanımlanmaktadır. Bu düşmanca eylemlerin yıldırma olabilmesi için en az 6 aylık süre ile gerçekleşmesi gerekmekte ve psişik, psikosomatik ve sosyal mutsuzluk gibi sonuçlarının olması beklenmektedir (Leymann, 1990, s. 120).

Haksız suçlamalar, küçük düşürmeler, genel tacizler ve duygusal eziyetler, yıldırma kapsamında değerlendirilebilecek kötü niyetli eylemlerdir (Davenport, Swartz, \& Elliot, 2003, p. 22). Acımasız, zalim veya kötü niyetli girişimlerle tekrarlanan bu davranışlar, çalışanları küçük düşürmektedir (Takaki et al. 2010, p. 74). Genel olarak yıldırmanın kötü yönetim, stresli iş ortamı, monoton çalışma, yöneticinin yıldırmayı görmezden gelmesi gibi örgütsel sebepleri bulunmaktadır (Davenport, Swartz, \& Elliot, 2003, p. 47).

Yıldırma ile ilgili rolleri oynayan üç grup insan bulunmaktadır: Yıldırma davranışını uygulayanlar, yıldırma mağdurları ve yıldırma izleyicileri (Tınaz, 2006, s. 57). İzleyiciler yıldırma eylemlerine doğrudan müdahalede bulunmayıp, genellikle örgüt içindeki gerilim 
karşısında sessiz kalırlar. Ancak, eylemler karşısındaki tepkisizlik, en az yıldırmayı uygulamak kadar sorunlu bir tutum olarak değerlendirilmektedir (Çarıkçı ve Yavuz, 2009, s. 49).

Sağlık sektöründe yıldırmanın diğer hizmet sektörleriyle karşılaştırıldığında 16 kat daha fazla olduğu tespit edilmiştir (Kingma, 2001, p. 129). Yapılan çalışmalar sağlık çalışanları içinde hemşirelerin daha fazla yıldırmaya uğradığını ortaya koymaktadır (Somani, Karmaliani, Farlane, Asad, \& Hirani, 2015, p. 235; Öztürk, Sökmen, Yılmaz, \& Cilingir, 2008, s. 438; Hegney, Plank, \& Parker, 2003, p. 262). Hemşireler daha çok fiziksel şiddete maruz kalırken, idari personel daha çok sözel şiddete maruz kalmaktadır (Ferrinho, 2003, p. 6). Sağlık sektöründe yıldırma kaynağının genellikle hasta olduğu düşünülmektedir, ancak üst düzey yöneticiler ve meslektaşlar da yıldırmaya sebep olabilmektedir (Okanlı, Karakaş, \& Özkan, 2011, s. 608; Beech ve Leather, 2006, p. 28).

Sağlık kurumlarındaki sert çalışma koşulları, vardiyalı çalışma, yetersiz ücretler ve mesleki ilerlemedeki adaletsizlikler yıldırmayı tetikleyebilmektedir (Davenport, Swartz, \& Elliot, 2003). Sağlık hizmetlerinde kalitenin ve üretim çıktısının diğer sektörlere göre daha belirsiz olması ve üstlerin astları üzerinde daha fazla yaptırım gücüne sahip olması da yıldırma davranışının daha fazla görülmesine sebep olmaktadır (Hubert ve Veldhoven, 2001, p. 422423). Hastanelerde özellikle kliniklerde amir otoritesi belirgindir (Polat ve Pakiş, 2012, s. 213) ve örgüt içinde yaşanan çatışmalarda, yönetim direkt çatışma içinde yer alması sebebiyle bu durum yıldırma sebebi olabilmektedir (Dikmetaş, Top, \& Ergin, 201, s. 3).

Yıldırma mağdurları hem duygusal hem de fiziksel olarak yıpranmaktadırlar (Duffy ve Sperry, 2007, p. 399; Hecker, 2007, p. 440). Bu kişiler genellikle örgütte izole olarak yaşamakta ve her an işten ayrılmaya hazır beklemektedirler (Leymann, 1990, p. 119-120). İşten atılma tehdidiyle de yaşayan mağdurlar, bu sebeple endişe, depresyon, uykusuzluk gibi ciddi sağlık sorunları yaşayabilmektedir (Quine, 1999, p. 231). Yıldırmaya maruz kalan çalışanların daha fazla hastalık izni aldığı ve motivasyonlarının daha düşük olduğu gözlenmektedir. Bu durum da örgütlerde üretkenlik azalmasına sebep olmaktadır.

\section{Araştırma}

\subsection{Araştırmanın Amacı}

$\mathrm{Bu}$ çalışmanın amacı, bir üniversite hastanesinde görev yapan sekreterlerin yıldırmaya maruz kalma düzeylerini belirlemek ve yıldırmaya maruz kalma düzeylerinin çeşitli demografik özelliklere göre farklılaşıp farklılaşmadığını ortaya koymaktır. 


\subsection{Araştırmanın Kapsamı}

Araştırmanın evreni, Türkiye'nin başkenti olan Ankara'da bulunan bir üniversiteye ait üç hastanenin polikliniklerinde ve kliniklerinde sekreter olarak çalışan kişileri kapsamaktadır. Hasta ve yakınlarıyla yüz yüze iletişim, otoriteler arası etkileşim ve multidisipliner çalışma sistemi gibi nedenlerle sekreterlerin aynı çalışma koşullarına sahip olmadığı düşünülerek yönetici sekreterleri, arşiv sekreterleri, satın alma ve bilgi işlem birimlerinde çalışan sekreterler kapsam dışı bırakılmıştır. Toplamda 201 sekreterden 160 kullanılabilir anket (\%80) elde edilmiştir. Veri toplama süreci 1 Aralık 2014 - 31 Aralık 2014 tarihleri arasında anketler sekreterlere dağıtılarak belirli bir süre sonra toplanmıştır. Bütün katılımcıların aydınlatılmış onamı alınmıştır. Araştırma, çalışmanın gerçekleştirildiği üniversitenin etik komisyonu tarafından onaylanmıştır.

\subsection{Veri Toplama Araçları}

Çalışmada veri toplama aracı olarak bir ölçek ve çalışanların sosyo-demografik özelliklerinden oluşan bir anket formu kullanılmıştır. Anketin ilk bölümünde sekreterlerin yıldırma düzeyini belirlemek için "LIPT (Leymann Inventory of Psychological Terrorization) Ölçeği” kullanılmıştır (Leymann, 1990). Alanyazın incelendiğinde, yıldırma davranışlarını ölçmeye yönelik pek çok çalışmada bu ölçeğin kullanıldığı görülmektedir (Köse ve Uysal, 2010; Tengilimoğlu ve Mansur, 2009; İbicioğlu et al. 2009, Çöl, 2008).

Ölçekte yer alan 45 ifadeden sadece herhangi birinde y1ldırmaya maruz kalma durumunun saptanması durumunda, çalışan yıldırma mağduru olarak kabul edilmektedir. Ölçek; iletişim kurma olanağını etkilemeye yönelik davranışlar, sosyal ilişkilere saldırılar, itibara saldırılar, mesleki durumu etkileyen saldırılar ve doğrudan sağlığı etkileyen saldırılar boyutlarından oluşmaktadır.

Öncelikle, araştırmada kullanılan ölçeğin güvenilirliği hesaplanmış ve ölçeğin genel Cronbach's Alpha değeri 0,96 bulunmuştur. Çöl (2008) tarafından sağlık çalışanları üzerinde yapılan bir çalışmada aynı ölçek kullanılmış ve Cronbach's Alpha değeri 0,85 olarak bulunmuştur. Kamu personeli üzerinde yapılan bir başka çalışmada aynı ölçeğin Cronbach’s Alpha değeri 0,95 olarak tespit edilmiştir (Köse ve Uysal, 2010). Bu çalışmada boyutlar bazında güvenilirlik değerlendirildiğinde, Cronbach's Alpha değerleri 0,60-0,93 arasında değişmektedir (Tablo 2).

Y1ldırma ile ilgili ifadeler, "her gün, haftada en az birkaç kez, ayda birkaç kez, yılda birkaç kez ve hiçbir zaman" şeklindeki beş seçenek ile değerlendirilmektedir (Her gün=1, Hiçbir zaman=5). Cevapların 1'e yaklaşması sekreterlerin her gün yıldırmaya maruz 
kaldıklarını gösterirken, cevapların 5'e yaklaşması hiç yıldırmanın olmadığını belirtmektedir. Sekreterlerden anket formundaki ifadelere cevap verirken, "altı ay süreklilik gösterecek şekilde" ne sıklıkta maruz kaldıklarını düşünmeleri istenmiştir.

\subsection{Verilerin Analizi}

Anketten elde edilen verilerin analizinde SPSS 20.0 paket programından yararlanılarak; tanımlayıcı istatistiksel yöntemler, iki ortalama arasındaki farkın önemlilik testi, ikiden fazla bağımsız grubun ortalamalarını karşılaştırmak için tek yönlü varyans analizi (ANOVA) ve tek yönlü varyans analizinde farklılığın hangi gruptan kaynaklandığının belirlenmesi amacıyla Tukey testi; ikiden fazla grupta parametrik koşulların sağlanmadığı durumlarda (bazı gruplara düşen gözlem sayısının 30'un altında olması) Kruskal Wallis Varyans Analizi yöntemi ve tek değişkenli analizlerde istatistiksel olarak anlamlı şekilde farklılaştığı tespit edilen değişkenlerin yıldırmaya maruz kalma üzerindeki etkisinin belirlenmesi amacıyla yürütülen çoklu doğrusal regresyon analizi kullanılmıştır.

\subsection{Araştırma Bulguları}

Araştırmaya katılan sekreterlerin 87,5'i kadın, \%50,3'ü 32 yaş ve altında, \%53,8’i ön lisans mezunu ve \%68,1'i evlidir. Katılımcıların \%57'si poliklinikte çalışmakta, \%43,9'u 10 yıldan daha fazla toplam çalışma süresine sahip ve \%39,8'i 5 yıldan daha az süredir aynı çalışma biriminde çalışmaktadır (Tablo 1).

Tablo: 1

Sekreterlere İlişkin Tanımlayıcı Özellikler $(\mathrm{n}=160)$

\begin{tabular}{|l|c|c|}
\hline Değişkenler & Sayı & Yüzde \\
\hline Cinsiyet & \multicolumn{2}{|c|}{} \\
\hline Kadın & 140 & 87,5 \\
\hline Erkek & 20 & 12,5 \\
\hline Yaş (Yul) & 80 & 50,3 \\
\hline$\leq 32$ & 79 & 49,7 \\
\hline$\geq 33$ & \multicolumn{2}{|l}{} \\
\hline Ĕ̈itim Durumu & \multicolumn{2}{|l|}{} \\
\hline
\end{tabular}




\begin{tabular}{|c|c|c|}
\hline Lise ve Dengi & 15 & 9,4 \\
\hline Ön Lisans & 86 & 53,8 \\
\hline Lisans ve Lisansüstü & 59 & 36,8 \\
\hline \multicolumn{3}{|l|}{ Medeni Durum } \\
\hline Bekâr & 51 & 31,9 \\
\hline Evli & 109 & 68,1 \\
\hline \multicolumn{3}{|l|}{ Çalışılan Birim } \\
\hline Poliklinik & 90 & 57,0 \\
\hline Klinik & 39 & 24,6 \\
\hline Biyokimya ve Radyoloji Laboratuvarı & 29 & 18,4 \\
\hline \multicolumn{3}{|l|}{ Toplam Çalışma Süresi (Yıl) } \\
\hline$<5$ & 45 & 28,7 \\
\hline $5-10$ & 43 & 27,4 \\
\hline$>10$ & 69 & 43,9 \\
\hline \multicolumn{3}{|l|}{ Birimde Çalışma Süresi (Yıl) } \\
\hline$<5$ & 62 & 39,8 \\
\hline $5-10$ & 42 & 26,9 \\
\hline$>10$ & 52 & 33,3 \\
\hline TOPLAM & 160 & 100,0 \\
\hline
\end{tabular}

Çalışmada kullanılan ölçeğin boyutları dikkate alınarak hesaplanan ortalama ve standart sapmaları Tablo 2'de görülmektedir. Hastanede çalışan sekreterlerin yıldırmaya maruz kalma düzeyleri genel olarak düşük düzeydedir $(4,52 \pm 0,60)$. Sekreterlerin iletişim kurma olanağını hedef almaya yönelik davranışlara maruz kalma düzeylerinin $(4,21 \pm 0,81)$ en yüksek ve doğrudan sağlığını etkileyen davranışlara maruz kalma düzeylerinin $(4,86 \pm 0,32)$ en düşük olduğu tespit edilmiştir.

Tablo: 2

Yıldırma Ölçeğinin Boyutlara Göre Ortalamaları ve Cronbach's Alpha Değerleri

\begin{tabular}{|l|c|c|c|}
\hline Ölçek Boyutları & $\begin{array}{c}\text { İfade } \\
\text { Sayısı }\end{array}$ & Ort. \pm S.S. & $\begin{array}{c}\text { Cronbach' } \\
\text { S Alpha }\end{array}$ \\
\hline $\begin{array}{l}\text { İletişim Kurma Olanağını Hedef Almaya Yönelik } \\
\text { Davranışlar }\end{array}$ & 11 & $4,21 \pm 0,81$ & 0,90 \\
\hline Sosyal Hayatı Hedef Almaya Yönelik Davranışlar & 5 & $4,62 \pm 0,63$ & 0,76 \\
\hline $\begin{array}{l}\text { İtibarını ve Saygınlığını Hedef Almaya Yönelik } \\
\text { Davranışlar }\end{array}$ & 15 & $4,62 \pm 0,63$ & 0,93 \\
\hline Mesleki Durumunu Hedef Almaya Yönelik Davranışlar & 9 & $4,48 \pm 0,78$ & 0,90 \\
\hline Doğrudan Sağlığı Etkileyen Davranışlar & 5 & $4,86 \pm 0,32$ & 0,60 \\
\hline Toplam & 45 & $4,52 \pm 0,60$ & 0,96 \\
\hline
\end{tabular}

* Ort: Aritmetik Ortalama, S.S: Standart Sapma 
Sekreterlerin cinsiyete ve yaşa göre yıldırmaya maruz kalma düzeylerine ilişkin boyutların ortalamaları, iki ortalama arasındaki farkın önemlilik testi ile test edilmiş; cinsiyet ve yaşın istatistiksel olarak anlamlı farklılık oluşturmadığı tespit edilmiştir (p>0,05). Katılımcıların yıldırmaya maruz kalma düzeyleri boyutlarına ilişkin ortalamaları toplam çalışma süresi ve çalışılan birimde çalışma süresine göre ANOVA testi ile karşılaştırılmış; her iki değişkene göre de sekreterlerin yıldırma düzeylerinin anlamlı farklılık göstermediği belirlenmiştir ( $\mathrm{p}>0,05)$ (Tablo 3).

Eğitim durumuna göre yıldırma boyutları Kruskal Wallis Varyans Analizi ile incelendiğinde, eğitimin istatistiksel olarak anlamlı farklılık oluşturduğu tespit edilmiştir. Sosyal hayatı hedef almaya yönelik davranışlar boyutunda, lisans ve lisansüstü eğitim düzeyine sahip sekreterlerin $(4,52 \pm 0,70)$ yıldırmaya maruz kalma düzeylerinin lise $(4,57 \pm 0,71)$ ve ön lisans düzeyinde $(4,70 \pm 0,54)$ eğitime sahip sekreterlerden daha yüksek olduğu belirlenmiştir $\left(\chi^{2}=7,150 ; p=0,028\right)$ (Tablo 3).

Medeni duruma göre yıldırmaya maruz kalma düzeyinde farklılık olup olmadığı iki ortalama arasındaki farkın önemlilik testi ile test edilmiş; bekâr ve evli sekreterlerde yıldırmaya maruz kalma düzeyinin farklı olduğu saptanmıştır. Mesleki durumunu hedef almaya yönelik davranışlar boyutunda, bekâr sekreterlerin $(4,27 \pm 0,95)$ evli sekreterlere göre $(4,57 \pm 0,68)$ yıldırmaya daha fazla maruz kaldıkları belirlenmiştir $(\mathrm{t}=-2,248 ; \mathrm{p}=0,026)$. Doğrudan sağlığ etkileyen davranışlar boyutunda da, bekâr sekreterlerin yıldırmaya maruz kalma puan ortalamalarının $(4,77 \pm 0,42)$ evli sekreterlerden $(4,89 \pm 0,26)$ daha yüksek olduğu saptanmıştır $(\mathrm{t}=-2,154 ; \mathrm{p}=0,033)$ (Tablo 3).

Tablo: 3

Sekreterlerin Çeşitli Değişkenlere Göre Yıldırma Boyutlarına Maruz Kalma Düzeyleri

\begin{tabular}{|c|c|c|c|c|c|}
\hline Değișkenler & $\begin{array}{c}\text { İletişim Kurma } \\
\text { Olanağını Hedef } \\
\text { Almaya Yönelik } \\
\text { Davranışlar }\end{array}$ & $\begin{array}{c}\text { Sosyal Hayatı } \\
\text { Hedef Almaya } \\
\text { Yönelik } \\
\text { Davranıșlar }\end{array}$ & $\begin{array}{c}\text { İtibarını ve } \\
\text { Saygınlığını Hedef } \\
\text { Almaya Yönelik } \\
\text { Davranışlar }\end{array}$ & $\begin{array}{c}\text { Mesleki } \\
\text { Durumunu Hedef } \\
\text { Almaya Yönelik } \\
\text { Davranıșlar }\end{array}$ & $\begin{array}{c}\text { Doğrudan Sağlığı } \\
\text { Etkileyen } \\
\text { Davranışlar }\end{array}$ \\
\hline & Ort. \pm S.S. & Ort. \pm S.S. & Ort. \pm S.S. & Ort. \pm S.S. & Ort. \pm S.S. \\
\hline \multicolumn{6}{|l|}{ Cinsiyet } \\
\hline Kadın & $4,19 \pm 0,82$ & $4,59 \pm 0,65$ & $4,60 \pm 0,66$ & $4,45 \pm 0,81$ & $4,85 \pm 0,33$ \\
\hline \multirow[t]{2}{*}{ Erkek } & $4,59 \pm 0,73$ & $4,84 \pm 0,27$ & $4,71 \pm 0,38$ & $4,66 \pm 0,51$ & $4,89 \pm 0,28$ \\
\hline & $\mathrm{t}=-0,962 ; \mathrm{p}=0,337$ & $\mathrm{t}=-1,677 ; \mathrm{p}=0,096$ & $\mathrm{t}=-0,707 ; \mathrm{p}=0,481$ & $\mathrm{t}=-1,091 ; \mathrm{p}=0,277$ & $\mathrm{t}=-0,471 ; \mathrm{p}=0,638$ \\
\hline \multicolumn{6}{|l|}{ Yaş } \\
\hline$\leq 32$ & $4,21 \pm 0,85$ & $4,63 \pm 0,64$ & $4,62 \pm 0,62$ & $4,38 \pm 0,83$ & $4,83 \pm 0,33$ \\
\hline \multirow[t]{2}{*}{$\geq 33$} & $4,20 \pm 0,78$ & $4,61 \pm 0,61$ & $4,61 \pm 0,64$ & $4,57 \pm 0,73$ & $4,88 \pm 0,32$ \\
\hline & $\mathrm{t}=0,015 ; \mathrm{p}=0,988$ & $\mathrm{t}=0,200 ; \mathrm{p}=0,842$ & $\mathrm{t}=0,047 ; \mathrm{p}=0,962$ & $\mathrm{t}=-1,502 ; \mathrm{p}=0,135$ & $\mathrm{t}=-0,832 ; \mathrm{p}=0,407$ \\
\hline \multicolumn{6}{|l|}{ Ĕgitim Durumu } \\
\hline Lise ve dengi (1) & $4,08 \pm 0,80$ & $4,57 \pm 0,71$ & $4,59 \pm 0,53$ & $4,56 \pm 0,70$ & $4,81 \pm 0,35$ \\
\hline Ön lisans (2) & $4,33 \pm 0,74$ & $4,70 \pm 0,54$ & $4,69 \pm 0,51$ & $4,54 \pm 0,75$ & $4,85 \pm 0,36$ \\
\hline
\end{tabular}




\begin{tabular}{|c|c|c|c|c|c|}
\hline $\begin{array}{l}\text { Lisans ve } \\
\text { Lisansüstü (3) }\end{array}$ & $4,06 \pm 0,88$ & $4,52 \pm 0,70$ & $4,52 \pm 0,79$ & $4,37 \pm 0,86$ & $4,87 \pm 0,27$ \\
\hline & $\chi^{2}=4,490 ; p=0,106$ & $\begin{array}{c}\chi^{2}=7,150 ; \mathbf{p}=\mathbf{0 , 0 2 8} \\
1-3 ; p=0,023\end{array}$ & $\chi^{2}=4,280 ; p=0,118$ & $\chi^{2}=2,541 ; p=0,281$ & $\chi^{2}=0,758 ; p=0,684$ \\
\hline \multicolumn{6}{|l|}{ Medeni Durum } \\
\hline Bekâr & $4,08 \pm, 89$ & $4,49 \pm 0,82$ & $4,49 \pm 0,86$ & $4,27 \pm 0,95$ & $4,77 \pm 0,42$ \\
\hline \multirow[t]{2}{*}{ Evli } & $4,27 \pm 0,76$ & $4,68 \pm 0,49$ & $4,68 \pm 0,48$ & $4,57 \pm 0,68$ & $4,89 \pm 0,26$ \\
\hline & $\mathrm{t}=-1,406 ; \mathrm{p}=0,162$ & $\mathrm{t}=-1,794 ; \mathrm{p}=0,075$ & $\mathrm{t}=-1,686 ; \mathrm{p}=0,094$ & $\mathrm{t}=-2,248 ; \mathbf{p}=\mathbf{0 , 0 2 6}$ & $\mathrm{t}=-2,154 ; \mathbf{p}=\mathbf{0 , 0 3 3}$ \\
\hline \multicolumn{6}{|l|}{ Çalışılan Birim } \\
\hline Poliklinik (1) & $4,07 \pm 0,82$ & $4,63 \pm 0,54$ & $4,53 \pm 0,68$ & $4,37 \pm 0,85$ & $4,80 \pm 0,39$ \\
\hline Klinik (2) & $4,25 \pm 0,90$ & $4,46 \pm 0,86$ & $4,62 \pm 0,70$ & $4,43 \pm 0,83$ & $4,88 \pm 0,24$ \\
\hline \multirow{2}{*}{$\begin{array}{l}\text { Biyokimya ve } \\
\text { Radyoloji (3) }\end{array}$} & $4,55 \pm 0,51$ & $4,77 \pm 0,44$ & $4,86 \pm 0,22$ & $4,84 \pm 0,30$ & $4,97 \pm 0,08$ \\
\hline & $\begin{array}{c}\mathrm{F}=4,081 ; \mathbf{p}=\mathbf{0 , 0 1 9} \\
1-3 ; p=0,015\end{array}$ & $\mathrm{~F}=2,156 ; \mathrm{p}=0,119$ & $\mathrm{~F}=3,001 ; \mathrm{p}=0,053$ & $\begin{array}{c}\mathrm{F}=4,138 ; \mathrm{p}=\mathbf{0 , 0 1 8} \\
1-3 ; \mathrm{p}=0,014\end{array}$ & $\begin{array}{c}\mathrm{F}=3,374 ; \mathrm{p}=\mathbf{0 , 0 3 7} \\
1-3 ; \mathrm{p}=0,035\end{array}$ \\
\hline \multicolumn{6}{|l|}{$\begin{array}{l}\text { Toplam Çalışma } \\
\text { Süresi (Yıl) }\end{array}$} \\
\hline$<5$ & $4,21 \pm 0,82$ & $4,68 \pm 0,49$ & $4,63 \pm 0,57$ & $4,38 \pm 0,85$ & $4,78 \pm 0,39$ \\
\hline $5-10$ & $4,17 \pm 0,91$ & $4,56 \pm 0,73$ & $4,64 \pm 0,64$ & $4,51 \pm 0,71$ & $4,91 \pm 0,24$ \\
\hline \multirow[t]{2}{*}{$>10$} & $4,20 \pm 0,75$ & $4,60 \pm 0,63$ & $4,58 \pm 0,68$ & $4,51 \pm 0,81$ & $4,86 \pm 0,33$ \\
\hline & $\mathrm{F}=0,033 ; \mathrm{p}=0,968$ & $\mathrm{~F}=0,422 ; \mathrm{p}=0,656$ & $\mathrm{~F}=0,174 ; \mathrm{p}=0,841$ & $\mathrm{~F}=0,459 ; \mathrm{p}=0,633$ & $\mathrm{~F}=1,877 ; \mathrm{p}=0,156$ \\
\hline \multicolumn{6}{|l|}{$\begin{array}{l}\text { Birimde Çalışma } \\
\text { Süresi (Yıl) }\end{array}$} \\
\hline$<5$ & $4,20 \pm, 85$ & $4,60 \pm 0,55$ & $4,62 \pm 0,58$ & $4,40 \pm 0,78$ & $4,84 \pm 0,33$ \\
\hline $5-10$ & $4,24 \pm 0,85$ & $4,58 \pm 0,82$ & $4,64 \pm 0,64$ & $4,48 \pm 0,84$ & $4,86 \pm 0,37$ \\
\hline \multirow[t]{2}{*}{$>10$} & $4,14 \pm 0,74$ & $4,65 \pm 0,53$ & $4,56 \pm 0,71$ & $4,53 \pm 0,77$ & $4,87 \pm 0,29$ \\
\hline & $\mathrm{F}=0,179 ; \mathrm{p}=0,836$ & $\mathrm{~F}=0,197 ; \mathrm{p}=0,822$ & $\mathrm{~F}=0,217 ; \mathrm{p}=0,805$ & $\mathrm{~F}=0,419 ; \mathrm{p}=0,658$ & $\mathrm{~F}=0,127 ; \mathrm{p}=0,881$ \\
\hline
\end{tabular}

* Ort: Aritmetik Ortalama, S.S: Standart Sapma

Sekreterlerin yıldırmaya maruz kalma düzeyleri alt boyutlarına ilişkin ortalamalarını çalışılan birime göre karşılaştıran ANOVA testi sonuçları incelendiğinde, iletişim kurma olanağını hedef almaya yönelik davranışlar $(F=4,081 ; p=0,019)$, mesleki durumunu hedef almaya yönelik davranışlar $(F=4,138 ; p=0,018)$ ve doğrudan sağlığ 1 etkileyen davranışlar $(\mathrm{F}=3,374 ; \mathrm{p}=0,037)$ boyutlarında istatistiksel olarak anlamlı farklılıklar tespit edilmiştir. Farklılığın hangi gruplardan kaynaklandığını tespit etmek amacıyla yürütülen Tukey testi sonuçlarına göre, poliklinik sekreterleri, özellikle biyokimya ve radyoloji laboratuvarlarında çalışan sekreterlere göre, daha yüksek düzeyde yıldırmaya maruz kalmaktadır (Tablo 3).

Tablo 4'te sekreterlerin tek değişkenli analizlerde istatistiksel olarak anlamlı şekilde farklılaştığı tespit edilen eğitim, medeni durum ve çalışılan birimin yıldırmaya maruz kalma düzeyleri üzerindeki etkisinin belirlenmesi amacıyla yürütülen çoklu doğrusal regresyon analizi sonuçları verilmektedir. Bağımsız değişkenler niteliksel olmaları nedeniyle göstermelik (dummy) değişken kullanılarak regresyon modeline alınmışlardır. Regresyon modelleri incelendiğinde sosyal hayatı hedef almaya yönelik davranışlar boyutu dışındaki diğer 5 modelin istatistiksel olarak anlamlı olduğu görülmektedir $(F=1.929 ; p>0.005)$. Regresyon modelleri incelendiğinde, lisans eğitim düzeyinde olanların lise eğitim düzeyine göre, bekârların evlilere göre ve poliklinik ve kliniklerde çalışanların diğer birimlerde çalışanlara göre yıldırmaya maruz kalma düzeyleri daha azdır. 
Tablo: 4

\section{Sekreterlerin Çeşitli Özelliklerinin Yıldırmaya Maruz Kalma Düzeyi Üzerindeki}

\section{Etkisine İlişkin Regresyon Analizi Sonuçları}

\begin{tabular}{|c|c|c|c|c|c|c|c|}
\hline $\begin{array}{l}\text { Bağımlı } \\
\text { Değișken }\end{array}$ & Bağımsız Değişkenler & B & $\begin{array}{l}\text { Standart } \\
\text { Hata }\end{array}$ & $\boldsymbol{\beta}$ & $\mathbf{t}$ & $\mathbf{p}$ & VIF \\
\hline \multirow{7}{*}{$\begin{array}{l}\text { İletişim } \\
\text { Kurma } \\
\text { Olanağını } \\
\text { Hedef } \\
\text { Almaya } \\
\text { Yönelik } \\
\text { Davranışlar }\end{array}$} & Sabit & 4,285 & 0,277 & & 15,489 & 0,000 & \\
\hline & Önlisans & 0,227 & 0,224 & 0,140 & 1,016 & 0,311 & 3,116 \\
\hline & Lisans & $-0,020$ & 0,230 & $-0,012$ & $-0,089$ & 0,929 & 3,098 \\
\hline & Evli & 0,157 & 0,139 & 0,090 & 1,134 & 0,258 & 1,039 \\
\hline & Poliklinik & $-0,425$ & 0,173 & $-0,259$ & $-2,456$ & 0,015 & 1,838 \\
\hline & Klinik & $-0,234$ & 0,198 & $-0,124$ & $-1,183$ & 0,239 & 1,823 \\
\hline & \multicolumn{2}{|l|}{$R=0,280$} & $F=2,593$ & $p<0,005$ & \multicolumn{3}{|c|}{ Durbin Watson $=1,776$} \\
\hline \multirow{7}{*}{$\begin{array}{l}\text { Sosyal } \\
\text { Hayatı } \\
\text { Hedef } \\
\text { Almaya } \\
\text { Yönelik } \\
\text { Davranışlar }\end{array}$} & Sabit & 4,580 & 0,215 & & 21,299 & 0,000 & \\
\hline & Önlisans & 0,095 & 0,174 & 0,076 & 0,547 & 0,585 & 3,116 \\
\hline & Lisans & $-0,072$ & 0,179 & $-0,056$ & $-0,401$ & 0,689 & 3,098 \\
\hline & Evli & 0,188 & 0,108 & 0,140 & 1,748 & 0,083 & 1,039 \\
\hline & Poliklinik & $-0,090$ & 0,135 & $-0,071$ & $-0,667$ & 0,505 & 1,838 \\
\hline & Klinik & $-0,254$ & 0,154 & $-0,175$ & $-1,648$ & 0,101 & 1,823 \\
\hline & \multicolumn{2}{|l|}{$R=0,244$} & $F=1,929$ & $p>0,005$ & \multicolumn{3}{|c|}{ Durbin Watson=1,973 } \\
\hline \multirow{7}{*}{$\begin{array}{l}\text { İtibarını ve } \\
\text { Saygınlığını } \\
\text { Hedef } \\
\text { Almaya } \\
\text { Yönelik } \\
\text { Davranışlar }\end{array}$} & Sabit & 4,704 & 0,219 & & 21,498 & 0,000 & \\
\hline & Önlisans & 0,082 & 0,177 & 0,064 & 0,463 & 0,644 & 3,116 \\
\hline & Lisans & $-0,079$ & 0,182 & $-0,060$ & $-0,433$ & 0,665 & 3,098 \\
\hline & Evli & 0,155 & 0,110 & 0,113 & 1,413 & 0,160 & 1,039 \\
\hline & Poliklinik & $-0,282$ & 0,137 & $-0,219$ & $-2,057$ & 0,041 & 1,838 \\
\hline & Klinik & $-0,186$ & 0,157 & $-0,126$ & $-1,187$ & 0,237 & 1,823 \\
\hline & \multicolumn{2}{|l|}{$R=0,249$} & $F=2,011$ & $p<0,005$ & \multicolumn{3}{|c|}{ Durbin Watson=1,783 } \\
\hline \multirow{7}{*}{$\begin{array}{l}\text { Mesleki } \\
\text { Durumunu } \\
\text { Hedef } \\
\text { Almaya } \\
\text { Yönelik } \\
\text { Davranışlar }\end{array}$} & Sabit & 4,729 & 0,269 & & 17,588 & 0,000 & \\
\hline & Önlisans & $-0,059$ & 0,217 & $-0,037$ & $-0,272$ & 0,786 & 3,116 \\
\hline & Lisans & $-0,204$ & 0,224 & $-0,125$ & $-0,913$ & 0,363 & 3,098 \\
\hline & Evli & 0,252 & 0,135 & 0,149 & 1,874 & 0,063 & 1,039 \\
\hline & Poliklinik & $-0,406$ & 0,168 & $-0,255$ & $-2,416$ & 0,017 & 1,838 \\
\hline & Klinik & $-0,353$ & 0,192 & $-0,193$ & $-1,837$ & 0,068 & 1,823 \\
\hline & \multicolumn{2}{|l|}{$R=0,282$} & $F=2,636$ & $p<0,005$ & \multicolumn{3}{|c|}{ Durbin Watson=1,724 } \\
\hline \multirow{7}{*}{$\begin{array}{l}\text { Doğrudan } \\
\text { Sağlığı } \\
\text { Etkileyen } \\
\text { Davranışlar }\end{array}$} & Sabit & 4,856 & 0,113 & & 42,812 & 0,000 & \\
\hline & Önlisans & 0,036 & 0,092 & 0,055 & 0,394 & 0,694 & 3,116 \\
\hline & Lisans & 0,059 & 0,094 & 0,086 & 0,625 & 0,533 & 3,098 \\
\hline & Evli & 0,095 & 0,057 & 0,134 & 1,678 & 0,095 & 1,039 \\
\hline & Poliklinik & $-0,154$ & 0,071 & $-0,231$ & $-2,169$ & 0,032 & 1,838 \\
\hline & Klinik & $-0,074$ & 0,081 & $-0,096$ & $-0,907$ & 0,366 & 1,823 \\
\hline & \multicolumn{2}{|l|}{$R=0,250$} & $F=2,023$ & $p<0,005$ & \multicolumn{3}{|c|}{ Durbin Watson=1,875 } \\
\hline \multirow{7}{*}{ Yildırma } & Sabit & 4,610 & 0,206 & & 22,376 & 0,000 & \\
\hline & Önlisans & 0,086 & 0,167 & 0,071 & 0,514 & 0,608 & 3,116 \\
\hline & Lisans & $-0,074$ & 0,171 & $-0,059$ & $-0,429$ & 0,668 & 3,098 \\
\hline & Evli & 0,172 & 0,103 & 0,132 & 1,667 & 0,098 & 1,039 \\
\hline & Poliklinik & $-0,306$ & 0,129 & $-0,251$ & $-2,375$ & 0,019 & 1,838 \\
\hline & Klinik & $-0,226$ & 0,147 & $-0,161$ & $-1,535$ & 0,127 & 1,823 \\
\hline & $R=0,281$ & & 2,603 & $p<0,005$ & Durbin & tson $=1$, & \\
\hline
\end{tabular}




\section{Tartışma}

Bu çalışmada, bir üniversiteye ait üç hastanede görev yapan sekreterlerin yıldırmaya maruz kalma düzeylerini belirlemek ve yıldırmaya maruz kalma düzeylerinin çeşitli demografik özelliklere göre farklılaşıp farklılaşmadığını ortaya koymak amaçlanmaktadır. Çalışma sonucunda hastanede çalışan sekreterlerin yıldırmaya maruz kalma düzeylerinin düşük olduğu tespit edilmiştir.

Araştırmaya katılan sekreterlerin iletişim kurma olanağını hedef almaya yönelik davranışlara maruz kalma düzeylerinin $(4,21 \pm 0,81)$ en yüksek olduğu belirlenmiştir. Hastane yöneticileri üzerinde yapılan bir çalışmada da, ortalamalar açısından bakıldığında, yöneticilerin en çok iletişim kurma olanağını hedef almaya yönelik davranışlara maruz kaldıkları belirlenmiştir (Karsavuran, 2014, s. 291). Sağlık çalışanlarının sürekli konuşmalarının kesilmesi, performansları ve iş ile ilgili şeyler konusunda olumsuz anlamda eleştiri alma, sürekli hataların dile getirilmesi gibi engeller ile çok sık karşılaştığı belirtilmektedir (Picakciefe, Acar, Colak, \& Kilic, 2015, p. 9). Bütün bu nedenlerin iletişim kurma olanağını hedef almaya yönelik davranışlar arasında olduğu söylenebilir. Sekreterler, yöneticileri ve çalışma arkadaşları tarafından iş performanslarını göstermelerine engel olunduğunu hissettiklerinde, yaptıkları iş sürekli eleştirildiğinde, sözlü, yazılı ve bakışlar ile tehditler aldıklarında, onlar açısından sağlıklı bir çalışma ve iletişim ortamının olmayacağı söylenebilir. Böyle bir ortamda bireysel ve örgütsel performans ve verimliliklerinin etkilenmesi muhtemeldir. Yıldırma davranışı, sağlık çalışanlarında stresi artırarak sunulan hizmetlerin kalitesini etkileyebilmektedir (JosipovićJelić, Stoini, \& Celić-Bunikić, 2005, p. 351). İşyerinde karşılaşılan psikososyal risklerin verimlilik ve ekonomik faaliyetlerde önemli kayıplara sebep olduğu; bireylerin sağlığını ve iyilik halini de olumsuz anlamda etkileyebileceği belirtilmektedir (Aytaç, Dursun, \& Gökçe, 2017, p. 374). Bu çalışmada, sekreterlerin doğrudan sağlığını etkileyen davranışlara maruz kalma düzeyleri $(4,86 \pm 0,32)$ en düşük düzeyde bulunmuştur.

Çalışmada, sekreterlerin yıldırmaya maruz kalma düzeylerinin cinsiyete göre istatistiksel olarak anlamlı fark göstermediği tespit edilmiştir $(p>0,05)$. Yapılan bir çalışmada da, kadınların çoğunlukta olduğu işyerlerinde psikolojik şiddetin daha sık görüldüğü bulgusunu elde edilmiştir (Carnero, Martínez, \& Sánchez-Mangas, 2010, p. 3779). Bir başka çalışmada ise bu durum, kadınların özellikle kendi cinslerine karşı pasif-saldırgan davranışlar göstermesiyle açıklanmaktadır (Björkqvist, 2001, p. 440). 
Çalışma bulgularından hareketle, sekreterlerin yıldırmaya maruz kalma düzeylerinin yaşa göre istatistiksel olarak anlamlı bir fark göstermediği bulgusu elde edilmiştir (p>0,05). Yapılan bir çalışmada, sağlık çalışanlarında 18-30 yaş arasında yıldırmanın daha çok görüldüğü tespit edilmiştir (Aytaç, Dursun, \& Gökçe, 2017, p. 372). Bir başka çalışmada da, havayolu şirketi çalışanlarında yaş ile yıldırmaya maruz kalma sıklığı arasında orta düzeye yakın ilişki olduğu ve artan yaşla birlikte yıldırmaya maruziyetin arttığı belirlenmiştir (Acar ve Dündar, 2008, s. 117).

Sekreterlerin yıldırmaya maruz kalma düzeylerinin toplam çalışma süresi ve çalışılan birimdeki çalışma süresine göre anlamlı farklılık göstermediği belirlenmiştir ( $p>0,05)$. Ancak, yapılan bir çalışmada, tıbbi sekreterlerin çalışma yaşamlarının ilk 2-5 yıllık döneminde hasta ve hasta yakınları tarafından yıldırma davranışlarına maruz kaldığı belirtilmektedir (Çakıroğlu ve Tengilimoğlu, 2014, s. 185). Diğer çalışmalarda da iş deneyimi az olanların yıldırmanın hedeflerine uygun riskte olduğu vurgulanmakta (Moreno Jimenez, Rodriguez Munoz, Salin, \& Morante, 2008, p. 105) ve genç ve deneyimsiz hemşirelerin mesleğin ilk yıllarında daha idealist ancak daha az özgüvenli olduğu ve üstleri tarafından yıldırmaya maruz kalmaya daha eğilimli olduğu vurgulanmaktadır (Çevik Akyıl, Tan, Saritaş, \& Altuntaş, 2012, s. 406).

Çalışmada, sekreterlerin yıldırmaya maruz kalma düzeylerinin eğitim durumuna göre istatistiksel olarak anlamlı fark gösterdiği tespit edilmiştir. Sosyal hayatı hedef almaya yönelik davranışlar boyutunda, lisans ve lisansüstü eğitim düzeyine sahip sekreterlerin yıldırmaya maruz kalma düzeyleri $(4,52 \pm 0,70)$, lise $(4,57 \pm 0,71)$ ve ön lisans düzeyinde $(4,70 \pm 0,54)$ eğitime sahip sekreterlerden daha yüksek bulunmuştur. Bir başka çalışmada, eğitim düzeyleri yükseldikçe kamu çalışanlarının "kendini gösterme ve iletişim", "sosyal ilişkilere saldırı" ve "yıldırmanın sonuçları"” boyutlarında daha fazla yıldırmaya maruz kaldıkları bulgusu elde edilmiştir (Köse ve Uysal, 2010, s. 272). Sosyal hayatı hedef almaya yönelik maruz kalma, çevredeki insanların konuşmaması, orada değilmiş gibi davranılması, başkalarına ulaşmanın engellenmesi gibi sebeplerle ortaya çıkmaktadır. Bu açıdan bakıldığında, hekim ve sağlık çalışanlarının hizmet sunumunu büyük ölçüde belirlediği bir sağlık sistemi içinde, sekreterler süreci kolaylaştıran bir ara eleman olarak görülmektedir. Hizmet sunumuna yönelik yapacakları sınırlı olmaktadır ve kimi zaman alınan kararlarda orada değilmiş gibi davranıldığını hissetmektedirler. Bu durum, yıldırmanın sekreterlerin iş ortamında sosyal hayatlarını etkilediği algisı oluşturabilmektedir.

Mesleki durumunu hedef almaya yönelik davranışlar boyutunda, bekâr sekreterlerin $(4,27 \pm 0,95)$ evli sekreterlere $(4,57 \pm 0,68)$ göre yıldırmaya daha fazla maruz kaldığ tespit edilmiştir. Doğrudan sağlığı etkileyen davranışlar boyutunda da, bekâr sekreterlerin 
$(4,77 \pm 0,42)$ evli sekreterlerden $(4,89 \pm 0,26)$ daha yüksek düzeyde yıldırmaya maruz kaldıkları bulgusu elde edilmiştir. Sağlık sektöründe hastane yöneticileri üzerinde yapılan bir başka çalışmada da, bekâr yöneticilerin yıldırmaya maruz kalma düzeyleri evlilerden daha yüksek bulunmuştur (Karsavuran, 2014, s. 289). Bir çalışmada, Türk kültüründe aile bağlarının ve sosyal desteğin güçlü olması nedeniyle mobbing olgusunun ciddi hastalıklara ve intiharlara yol açmayacağı belirtilmektedir (Koç ve Bulut, 2009, s. 68). Evli sekreterlerin yıldırmaya daha az maruz kalması, aile kuran sekreterlerin daha fazla ailesel sorunlar üzerinde durduğu ve sosyal aidiyetini aile üzerine kurduğu şeklinde açıklanabilir. Aynı davranışlara maruz kalsalar bile, bekâr sekreterler bu davranışları evli sekreterlerden daha kötü olarak algılıyor olabilirler.

Sekreterlerin yıldırmaya maruz kalma düzeyleri çalışılan birime göre karşılaştırılmış; iletişim kurma olanağını hedef almaya yönelik davranışlar, mesleki durumunu hedef almaya yönelik davranışlar ve doğrudan sağlığı etkileyen davranışlar boyutlarında istatistiksel olarak anlamlı farklılıklar tespit edilmiştir. Poliklinik sekreterleri, özellikle biyokimya ve radyoloji laboratuvarlarında çalışan sekreterlere göre, daha yüksek düzeyde yıldırmaya maruz kalmaktadır. Bu çalışma bulgularıyla tutarlı olarak, hemşireler üzerinde yapılan bir çalışmada da, poliklinikte çalışanların serviste çalışanlardan daha yüksek oranda yıldırmaya maruz kaldıkları bulgusu elde edilmiştir (Üye, 2009, s. 46). Poliklinikler, hasta ve hasta yakınları trafiğinin yoğun olduğu çalışma alanlarıdır ve bu sebeple diğer çalışanlarla ve birimlerle de iletişim yoğun olmaktadır. Bu sebeple, sekreterlerin yıldırmaya maruziyeti hastalardan kaynaklı olabilir. Tıbbi sekreterlerin büyük oranda hasta ve hasta yakınları tarafindan yıldırmaya maruz kaldıkları vurgulanmaktadır (Çakıroğlu ve Tengilimoğlu, 2014, s. 185).

Sekreterlerin eğitim, medeni durum ve çalışılan birimlerinin yıldırmaya maruz kalma düzeyleri üzerindeki etkisini belirlemek amacıyla çoklu doğrusal regresyon analizi yürütülmüştür. Sosyal hayatı hedef almaya yönelik davranışlar boyutu dışındaki diğer 5 modelin istatistiksel olarak anlamlı olduğu görülmüştür $(F=1.929 ; p>0.005)$. Çoklu doğrusal regresyon analizi sonucunda, lisans eğitim düzeyinde olanların lise eğitim düzeyine göre, bekârların evlilere göre ve poliklinik ve kliniklerde çalışanların diğer birimlerde çalışanlara göre yıldırmaya maruz kalma düzeyleri daha düşük bulunmuştur.

\section{Sonuç}

Çalışma sonucunda, hastanede çalışan sekreterlerin yıldırmaya maruz kalma düzeylerinin düşük olduğu tespit edilmiştir. Sekreterlerin iletişim kurma olanağını hedef almaya yönelik yıldırma davranışlarına daha fazla maruz kaldıkları belirlenmiştir. Sağlık kurumlarında hizmetin sunum aşamalarında iletişim oldukça önemlidir ve sekreterler hizmet 
sunum sürecinin önemli bileşenlerinden biridir. Dolayısıyla sekreterlerin çalıştıkları kurumda iletişim engeliyle karşılaştıklarını düşünmesi, hastane yönetimleri tarafından üzerinde durulması gereken konular arasındadır. Örgütün dışından gelecek ve tarafsız bir danışman, bu konuda mağdurlara destek olabilir. Yaşadıkları sorunlara ilişkin konuşabilecekleri imkânlar sağlanan çalışanlar, şikâyetleri dinlendiğinde ve bunlara çözüm bulunduğunda, daha mutlu olabilirler ve böylece örgüte daha fazla katma değer sağlayabilirler. Sekreterlerin görev ve sorumluluklarının tam olarak belirlenmesinin önemli olduğu düşünülmektedir. Hastane yönetimi, işe odaklanmayan ve sürekli devamsızlık yapan çalışanların bir sorun yaşayıp yaşamadıklarından emin olmalıdır. Hasta ve hasta yakınlarından kaynaklı yıldırma davranışını önlemek için hastane yönetimi tarafından broşürler bastırılarak hasta ve yakınlarına dağıtılabilir ve bekleme salonlarında broşürler bulundurulabilir. Hastane koridorlarında görülebilecek şekilde bu konuda yaptırımların olacağına yönelik bilinçlendirmeler yapılabilir.

Alanyazın incelendiğinde yıldırma çalışmalarının hemşirelik mesleğinde yoğunlaştığı ve diğer sağlık kurumları çalışanlarını inceleyen çalışma sayısının sınırlı olduğu görülmektedir. $\mathrm{Bu}$ yönüyle çalışmanın alana katkı sağlayacağı düşünülmektedir. Bununla birlikte, bu çalışmanın sonuçlarının hastanelerde çalışan tüm sekreterlere genellenmesi konusunda sınırlılıkları bulunmaktadır. Araştırma sadece Türkiye'nin bir ilinde ve bir üniversiteye ait hastanelerde çalışan sekreterler üzerinde yapılmıştır. Farklı sağlık kurumlarında ve farklı birimlerde çalışan sekreter üzerinde çalışmaların yapılması ve bulguların sonuçlarla ilişkilendirilmesi önerilir.

\section{Kaynakça}

Acar, A. B. \& Dündar, G. (2008). İşyerinde psikolojik yıldırmaya (mobbing) maruz kalma sıklığı ile demografik özellikler arasındaki ilişkinin incelenmesi. Ístanbul Üniversitesi İşletme Fakültesi Dergisi, 37(2), 111-120.

Aytac, S., Dursun, S., \& Gokce, A. (2017). Mobbing as a Psycho-social Risk at Work: A Study in Turkey. In Advances in Social \& Occupational Ergonomics (pp. 369-376). Springer International Publishing.

Baran, H. S., Zincirkıran, M., \& Tiftik, H. (2014). Hastanelerde çalışan hekimlerin tıbbi sekreterlere yönelik tutumları üzerine bir araştırma: Ankara örneği. Finans Politik ve Ekonomik Yorumlar, 51(588), 97-106. 
Beech, B., \& Leather, P. (2006). Workplace violence in the health care sector: A review of staff training and integration of training evaluation models. Aggression and Violent Behavior, 11(1), 27-43.

Björkqvist, K. (2001). Social defeat as a stressor in humans. Physiology \& Behavior, 73, 435442.

Carnero, M. A., Martínez, B., \& Sánchez-Mangas, R. (2010). Mobbing and its determinants: The case of Spain. Applied Economics, 42(29), 3777-3787.

Çevik Akyıl, R., Tan, M., Sarıtaş, S., \& Altuntaş, S. (2012). Levels of mobbing perception among nurses in Eastern Turkey. International Nursing Review, 59(3), 402-408.

Cobanoglu, S. (2005). Mobbing, İşyerinde Duygusal Saldırı ve Mücadele Yöntemleri. İstanbul: Sistem Matbaacilık.

Çakıroğlu, E., \& Tengilimoğlu, D. (2014). Mobbing (Yıldırma) davranışlarının tıbbi sekreterlerin tükenmişliği üzerine etkisi. Electronic Journal of Vocational Colleges, 4(3), 167-188.

Çarıkçı, İ. H., \& Yavuz H. (2009). Çalışanlarda mobbing (psikolojik şiddet) algısı: Sağlık sektörü çalışanları üzerine bir araştırma. Süleyman Demirel Üniversitesi Sosyal Bilimler Enstitüsü Dergisi. 10(2), 47-62.

Çöl, S.Ö. (2008). İşyerinde psikolojik şiddet: Hastane çalışanları üzerine bir araştırma, Çalışma ve Toplum, 19(4), 107-134.

Davenport, N., Swartz, R.D., \& Elliot, G.P. (2003). Mobbing İşyerinde Duygusal Taciz. İstanbul: Sistem Yayıncılık.

Dikmetaş, E., Top, M., \& Ergin, G. (2011). Asistan hekimlerin tükenmişlik ve mobbing düzeylerinin incelenmesi. Türk Psikiyatri Dergisi, 22(3), 137-149.

Duffy, M., \& Sperry, L. (2007). Workplace mobbing: Individual and family health consequences. The Family Journal, 15(4), 398-404.

Ferrinho, P., Biscaia, A., Fronteira, I., Craveiro, I., Antunes, A. R., Conceição, C., Flore, I., \& Santos, O. (2003). Patterns of perceptions of workplace violence in the Portuguese health care sector. Human Resources for Health, 1(1), 1-11.

Hecker, T. E. (2007). Workplace mobbing: A discussion for librarians. The Journal of Academic Librarianship, 33(4), 439-445.

Hegney, D., Plank, A. \& Parker, V. (2003). Workplace violence in nursing in Queensland, Australia: A self reported study. International Journal of Nursing Practice, 9(4), 261268. 
Hubert, A. B., \& Van Veldhoven, M. (2001). Risk sectors for undesirable behaviour and mobbing. European Journal of Work and Organizational Psychology, 10(4), 415-424.

İbicioğlu, H., Çiftçi, M., \& Derya, S. (2009). Örgütlerde yıldırma (Mobbing): Kamu sektöründe bir inceleme. Organizasyon ve Yönetim Bilimleri Dergisi, 1(2), 25-38.

Josipović-Jelić, Ž., Stoini, E., \& Celić-Bunikić, S. (2005). The effect of mobbing on medical staff performance. Acta Clinica Croatica, 44(4), 347-352.

Karsavuran, S. (2014). Sağlık sektöründe mobbing: Hastane yöneticileri üzerinde bir uygulama/mobbing in healthcare: An application to hospital managers. Mustafa Kemal Üniversitesi Sosyal Bilimler Enstitüsü Dergisi, 11(26), 271-296.

Kingma, M. (2001). Workplace violence in the health sector: A problem of epidemic proportion. International Nursing Review, 48, 129-130.

Koç, M. \& Bulut, H. U. (2009). Ortaöğretim öğretmenlerinde mobbing: Cinsiyet yaş ve lise türü değişkenleri açısından incelenmesi. International Online Journal of Educational Sciences, 1(1), 64-80.

Köse, S. \& Uysal Ş. (2010). Kamu personelinin yıldırma (mobbing) ve boyutları hakkındaki düşünceleri üzerine bir çalışma: Manisa Tarım İl Müdürlüğü örneği, Celal Bayar Üniversitesi Sosyal Bilimler Dergisi, 8(1), 261-276.

Leymann, H. (1990). Mobbing and psychological terror at workplaces. Violence and Victims, $5,119-126$.

Moreno Jimenez, B., Rodriguez Munoz, A., Salin, D., \& Morante, M. E. (2008), Workplace bullying in Southern Europe: Prevalence, Forms and Risk Groups in a Spanish Sample, International Journal of Organizational Behaviour, 13(2), 96-109.

Okanlı, A., Karakaş, S. A., \& Özkan, H. (2011). The relationship between mobbing and assertiveness in nurses. Journal of Society for Development in New Net Environment in $B \& H, 5(3), 609-615$.

Öztürk, H., Sökmen, S., Yılmaz, F., \& Çilingir, D. (2008). Measuring mobbing experiences of academic nurses: Development of a mobbing scale. Journal of the American Academy of Nurse Practitioners, 20(9), 435-442.

Picakciefe, M., Acar, G., Colak, Z., \& Kilic, I. (2015). The relationship between sociodemographic characteristics, work conditions, and level of mobbing of health workers in primary health care. Journal of Interpersonal Violence, 1-26. doi: $10.1177 / 0886260515586360$

Polat, O. \& Pakiş, I. (2012). Mobbing: İşyerinde psikolojik taciz, Acıbadem Üniversitesi Să̆llk Bilimleri Dergisi, 3(4), 211-217. 
Quine, L. (1999). Workplace bullying in NHS community trust: Staff questionnaire survey. BMJ, 318(7178), 228-232.

Somani, R., Karmaliani, R., Farlane, J. M., Asad, N., \& Hirani, S. (2015). Prevalence of bullying / mobbing behaviour among nurses of private and public hospitals in Karachi, Pakistan. International Journal of Nursing Education, 7(2), 235-239.

Takaki, J., Tsutsumi, A., Fujii, Y., Taniguchi, T., Hirokawa, K., Hibino, Y., Lemmer, RJ., Nashiwa, H., Wang, D.H., \& Ogino, K. (2010). Assessment of workplace bullying and harassment: reliability and validity of a Japanese version of the negative acts questionnaire. Journal of Occupational Health, 52(1), 74-81.

Tengilimoğlu, D. \& Köksal, A. (2013). Tıp Sekreterliği. Ankara: Seçkin Yayıncılık.

Tengilimoğlu, D. \& Mansur, F. (2009). İşletmelerde uygulanan mobbingin (psikolojik şiddet) örgütsel bağlılığa etkisi. Uluslararası İktisadi ve İdari Incelemeler Dergisi, 1(3), 69-84.

Tınaz, P. (2006). İşyerinde Psikolojik Taciz (Mobbing). İstanbul: Beta Yayıncılık.

Üye, C. (2009). Hemşirelerin yöneticileri tarafından mobbing davranışları ile karşılaşma durumlarının belirlenmesi (Yüksek Lisans Tezi). Haliç Üniversitesi, İstanbul.

Ünal, Ö. F., \& Karaoğul, Z. (2013). Psikolojik şiddetin örgütsel bağlılık üzerine etkisi: Büro sekreterleri üzerine bir araştırma, Süleyman Demirel Üniversitesi Sosyal Bilimler Enstitüsü Dergisi, Büro Yönetimi Özel Sayısı, 175-192.

Zukauskas, P., \& Vveinhardt, J. (2015). Diagnosis of mobbing as discrimination in employee relations. Engineering Economics, 64(4), 103-113. 